\title{
New semiquantitative ultrasonographic score for peripheral arterial disease assessment and its association with cardiovascular risk factors
}

\begin{abstract}
Luca Santoro ${ }^{1}$, Pietro Manuel Ferraro ${ }^{2}$, Andrea Flex ${ }^{1}$, Antonio Nesci ${ }^{1}$, Giuseppe De Matteis ${ }^{1}$, Angela Di Giorgio ${ }^{1}$, Vincenzo Zaccone ${ }^{1}$, Giovanni Gambaro ${ }^{2}$, Antonio Gasbarrini ${ }^{1}$ and Angelo Santoliquido ${ }^{1}$

The data concerning the distribution, extent and progression of peripheral arterial disease (PAD), as well as its association with traditional cardiovascular (CV) risk factors, have generally been obtained from studies of patients in advanced stages of the disease undergoing surgical or endovascular treatment. In this study, we have introduced a new semiquantitative ultrasonographic score (ultrasonographic lower limb atherosclerosis (ULLA) score) that is able to categorize lower limb atherosclerotic lesions at all stages of PAD. We then associated these ultrasonographic categories with a CV risk profile. We enrolled 320 consecutive subjects with symptoms suggestive of PAD or with known CV risk factors referring to our angiology unit between 1 July 2014 and 30 June 2015 for ultrasonographic evaluation of the lower limb arteries. Femoropopliteal and run-off segments were categorized together and separately based on their ultrasonographic characteristics. In univariate and multivariate analyses, the ULLA scores were significantly associated with the main CV risk factors, that is, age, male gender, cigarette smoking, arterial hypertension, diabetes, dyslipidemia, sedentary lifestyle, previous CV events and family history of CV disease, and also confirming the specific association of single risk factors with different segments of lower limb arteries. The proposed ULLA score enables a complete evaluation of the entire lower limb atherosclerotic burden, extending the results concerning the association of PAD with CV risk factors to all stages of the disease, including the early stages. It can be feasible that this new score will facilitate better evaluation of the progression of PAD and its prospective role in CV risk stratification. Hypertension Research (2016) 39, 868-873; doi:10.1038/hr.2016.88; published online 14 July 2016
\end{abstract}

Keywords: diagnosis; peripheral artery disease; risk factors/global assessment; ultrasound

\section{INTRODUCTION}

Atherosclerosis is a systemic, multifocal disease that represents the leading cause of death in Western countries. ${ }^{1}$ The risk factors contributing to its distribution, extent and progression in different organs (i.e., the heart, brain or limbs) and different segments (large and small vessels) are not identical. ${ }^{2-4}$ In particular, smoking and diabetes mellitus seem to be more strictly associated with lower limb atherosclerosis (termed peripheral arterial disease (PAD)), with respect to coronary heart and cerebrovascular districts, independently of the severity of the underlying atherosclerosis. ${ }^{5}$ Moreover, there are striking dissimilarities between the arterial regions of the lower extremities: smoking and hypercholesterolemia are closely related to the involvement of the iliac and femoropopliteal (proximal) district, whereas diabetes mellitus is closely related to the involvement of the infrageniculate (distal) district. ${ }^{6}$

The findings relating to the distribution pattern of peripheral atherosclerotic lesions generally have been obtained from studies of patients undergoing surgical or endovascular treatment for advanced stages of PAD (generally Fontaine stages III-IV), which correspond to the detection of hemodynamically significant lesions through instrumental imaging. Moreover, the diagnostic techniques used in these studies are typically limited to angiography or ankle-brachial index (ABI) evaluation, which are two methods that do not provide information about early atherosclerotic lesions and about the entire atherosclerotic burden. In medicine, there is an increased need to identify early lesions, which act as markers of vascular damage associated with increased cardiovascular (CV) risk; thus, searching only for signs of advanced PAD that can result in superficial findings. These considerations are relevant considering the recent involvement of $\mathrm{PAD}$ in $\mathrm{CV}$ risk stratification. In recent years, several imaging techniques, including ultrasonography, have been suggested to distinctly evaluate the entire arterial tree of the lower limbs, enabling atherosclerotic lesions to be identified at all disease stages.

Currently, no data evaluating the association between traditional $\mathrm{CV}$ risk factors and $\mathrm{PAD}$ consider all stages of $\mathrm{PAD}$, including early atherosclerotic lesions.

Therefore, the aims of this study are (i) to propose a new ultrasonographic score, the ULLA (ultrasonographic lower limb

${ }^{1}$ Department of Internal Medicine, Catholic University of Rome, Rome, Italy and ${ }^{2}$ Division of Nephrology and Dialysis, Catholic University of Rome, Rome, Italy Correspondence: Dr L Santoro, Department of Internal Medicine, Catholic University of Rome, Complesso Integrato Columbus, Via Giuseppe Moscati, 31 , 00168 Rome, Italy. E-mail: lu_santoro@libero.it

Received 9 February 2016; revised 16 April 2016; accepted 16 May 2016; published online 14 July 2016 
atherosclerosis) score, which categorizes atherosclerotic lesions of the lower limbs at all stages of $\mathrm{PAD}$, and (ii) to associate these ultrasonographic categories with CV risk profiles.

\section{PATIENTS AND METHODS}

\section{Patients}

All consecutive subjects with symptoms suggestive of PAD or with known CV risk factors who were referred to our angiology unit between 1 July 2014 and 30 June 2015 for ultrasonographic evaluation of the lower limb arteries were recruited for the study. The exclusion criterion was age $<18$ years.

$\mathrm{CV}$ risk factors included in the statistical model were age, gender, diabetes mellitus status, arterial hypertension status, dyslipidemia status, body mass index (BMI), cigarette smoking modeled as both number (packs per year) and smoking status ('never', 'former' and 'active'), sedentary lifestyle, previous CV events and family history of CV disease. The presence of diabetes mellitus status was determined based on the following indicators: fasting plasma glucose concentration (after 8 or more hours of no caloric intake) $\geqslant 126 \mathrm{mg} \mathrm{dl}^{-1}$; plasma glucose concentration $\geqslant 200 \mathrm{mg} \mathrm{dl}^{-1} 2 \mathrm{~h}$ after ingesting a $75 \mathrm{~g}$ oral glucose load in the morning after an overnight fast of at least $8 \mathrm{~h}$; symptoms of hyperglycemia (e.g., polyuria, polydipsia, polyphagia) and a random (casual, non-fasting) plasma glucose concentration $\geqslant 200 \mathrm{mg} \mathrm{dl}^{-1}$; or hemoglobin Alc level $\geqslant 6.5 \% .^{7}$ The presence of arterial hypertension status was defined by systolic blood pressure $>140 \mathrm{~mm} \mathrm{Hg}$ and/or diastolic blood pressure $>90 \mathrm{~mm} \mathrm{Hg}$ or in case of consumption of any antihypertensive drug. ${ }^{8}$ The presence of dyslipidemia status was defined by low-density lipoprotein cholesterol level $>130 \mathrm{mg} \mathrm{dl}^{-1}$, total cholesterol level $>200 \mathrm{mg} \mathrm{dl}^{-1}$, triglyceride level $>150 \mathrm{mg} \mathrm{dl}^{-1}$, high-density lipoprotein cholesterol level $<50 \mathrm{mg} \mathrm{dl}^{-1}$ or in case of consumption of any lipid-lowering drug. ${ }^{9}$

\section{Ultrasound lower limb evaluation}

Ultrasonographic examination was performed using a high-resolution Philips iU22 sonograph (Philips Medical Systems, Monza, Italy) and a linear 9-3 MHz transducer. Patients were placed in a supine position; the femoropopliteal and run-off segments were continuously scanned from the subinguinal region to the paramalleolar region with axial and sagittal scans. All segments were examined for their parietal characteristics, especially the presence of vessel wall calcifications and/or atherosclerotic plaques. In addition, flow velocity measurements were obtained using spectral Doppler imaging with an insonation angle of $60^{\circ}$ and color Doppler imaging. Arteries were grouped into femoropopliteal or proximal (common, superficial and deep femoral arteries, popliteal artery) and infrageniculate or distal (tibiofibular trunk, anterior and posterior tibial arteries, fibular artery) districts.

A new ultrasonographic, semiquantitative scoring system for disease severity assessment, the ULLA score, was proposed for assessing the proximal and distal districts. The lesions in the proximal district were categorized into six groups: (I) normal parietal characteristics (no vessel wall calcifications and/or atherosclerotic plaques), with normal flow velocity measurements; (II) presence of non-stenotic parietal calcifications, with normal flow velocity measurements; (III) presence of atherosclerotic plaques stenosing the artery by not $>30 \%$, with normal flow velocity measurements; (IV) presence of stenosing atherosclerotic plaques narrowing the lumen $>30 \%$ but $<70 \%$, with normal flow velocity measurements; $(\mathrm{V})$ presence of stenosing atherosclerotic plaques narrowing the lumen $>70 \%$, with alteration of flow velocity measurements; and (VI) complete occlusion of the lumen.

The lesions in the distal district were categorized into five groups: (I) normal parietal characteristics (no vessel wall calcifications and/or atherosclerotic plaques), with normal flow velocity measurements; (II) presence of non-stenotic parietal calcifications, with normal flow velocity measurements; (III) presence of non-stenotic atherosclerosis, with normal flow velocity measurements; (IV) presence of atherosclerosis, with alteration of flow velocity measurements; and (V) complete occlusion of the lumen. Non-stenotic distal district lesions characterized by normal flow velocity measurements were grouped together because of the reduced accuracy of this tool when making precise stenoses evaluations in small vessels and in cases of poor clinical significance.

All scans were performed by the same experienced vascular sonographer.

\section{Statistical analysis}

Between-group differences were assessed using an analysis of variance for normally distributed continuous variables, the Kruskal-Wallis test for non-normally distributed continuous variables and a $\chi^{2}$ test for nominal variables. The ULLA total severity score was defined as the highest of the

Table 1 Baseline characteristics of the study population by ULLA total severity score

\begin{tabular}{|c|c|c|c|c|c|c|c|}
\hline & 1 & /I & III & IV & $v$ & $V I$ & P-value \\
\hline Age, mean (s.d.) & $59(10)$ & $69(10)$ & $69(9)$ & $72(7)$ & $74(8)$ & $74(8)$ & $<0.001$ \\
\hline Gender & & & & & & & $<0.001$ \\
\hline Altered $\mathrm{ABI}$ & $2(6 \%)$ & 7 (8\%) & 10 (11\%) & 7 (26\%) & $34(54 \%)$ & 19 (100\%) & $<0.001$ \\
\hline BMI, mean (s.d.) & $27.2(5.1)$ & $27.3(3.9)$ & $27.7(4.9)$ & $28.9(4.9)$ & $26.1(3.5)$ & $25.8(2.9)$ & 0.043 \\
\hline Packs per year, median (IQR) & $3(0,11)$ & $0(0,8)$ & $15(0,30)$ & $11(0,36)$ & $23(0,38)$ & $45(18,60)$ & $<0.001$ \\
\hline Smoking status & & & & & & & $<0.001$ \\
\hline Diabetes & $3(8 \%)$ & $24(28 \%)$ & $26(29 \%)$ & $15(56 \%)$ & $31(49 \%)$ & $6(32 \%)$ & $<0.001$ \\
\hline Dyslipidemia & $17(47 \%)$ & $49(57 \%)$ & $60(67 \%)$ & $16(59 \%)$ & $39(62 \%)$ & $12(63 \%)$ & 0.42 \\
\hline CV family history & $28(78 \%)$ & $67(78 \%)$ & 75 (84\%) & $16(59 \%)$ & $50(79 \%)$ & $16(84 \%)$ & 0.15 \\
\hline Sedentary lifestyle & $5(14 \%)$ & $18(21 \%)$ & $27(30 \%)$ & $5(19 \%)$ & $26(41 \%)$ & $5(26 \%)$ & 0.025 \\
\hline CV events & $3(8 \%)$ & $12(14 \%)$ & $19(21 \%)$ & $8(30 \%)$ & $24(38 \%)$ & $10(53 \%)$ & $<0.001$ \\
\hline
\end{tabular}

Abbreviations: $\mathrm{ABI}$, ankle-brachial index; BMI, body mass index; CV, cardiovascular; ULLA, ultrasonographic lower limbs atherosclerosis. 
proximal or distal scores, regardless of the involvement of one or both legs; moreover, the proximal and distal scores were evaluated separately.

Associations between each CV risk factor and the ULLA scores were assessed with ordered logistic models. Models were further adjusted for age, gender and BMI, and the univariate and adjusted estimates of association are presented. The full set of analyses was repeated after the exclusion of participants with altered $\mathrm{ABI}$ (i.e., $\mathrm{ABI}<0.9$ ). All statistical analyses were performed with Stata MP 13.0 (StataCorp, College Station, TX, USA). A two-tailed $P$-value $<0.05$ was regarded as statistically significant.

\section{Ethical approval}

Written informed consent was obtained from all participants before their enrollment in the study. The study was performed in accordance with the Declaration of Helsinki and was approved by the ethics committee of the Catholic University of Rome (ethics committee reference number: 14725/2014).

\section{RESULTS}

Overall, 320 participants were included in the study; their baseline characteristics by total severity score are reported in Table 1.

Univariate and multivariate estimates of the association between $\mathrm{CV}$ risk factors and ULLA scores (total severity score and proximal and distal districts scores) are reported in Table 2.

In the univariate analyses, all the ULLA scores were significantly associated with age and male gender, but not with BMI. After adjusting for age, gender and BMI, there was a statistically significant association between the total severity score and pack-years of smoking $(P<0.001)$, smoking status $(P<0.001)$, arterial hypertension $(P=0.001)$, diabetes $(P=0.004)$, dyslipidemia $(P=0.04)$, sedentary lifestyle $(P=0.02)$ and previous $\mathrm{CV}$ events $(P=0.01)$; the association with family history of $\mathrm{CV}$ disease was marginally significant $(P=0.05)$. When the proximal and distal districts were considered separately, smoking status $(P=0.01)$ and dyslipidemia $(P=0.02)$ were selectively associated with the proximal district score, whereas family history of $\mathrm{CV}$ disease $(P=0.03)$ and sedentary lifestyle $(P=0.002)$ were selectively associated with the distal district score. Packs per year of smoking, arterial hypertension and diabetes were significantly associated with both proximal and distal district scores. However, for arterial hypertension, the magnitude of the association was larger for the proximal district score (odds ratio (OR) 2.26 vs. 1.90), whereas for diabetes it was larger for the distal district score (OR 2.41 vs. 1.75).

After excluding those participants with altered ABI $(n=79)$ or PAD symptoms $(n=39)$ from the analysis, the results remained substantially unaltered, except for previous CV events, which was no longer associated with the scores of subjects with normal ABI (Tables 3 and 4).

\section{DISCUSSION}

Most studies of atherosclerosis identify patients as affected by $\mathrm{PAD}$ only if they report symptoms suggestive of $\mathrm{PAD}$ or provide instrumental demonstration of lower limb perfusion deficits. This trend may explain why PAD remains, probably, the most underdiagnosed and least aggressively managed atherosclerotic disease. However, several studies have indicated that patients with PAD have an increased risk for all-cause mortality and for death from coronary heart disease than those without PAD. ${ }^{10-12}$ It is important to address the presence of atherosclerotic lesions in the lower limb districts before they become apparent as a clinical PAD syndrome. Currently, the presence of subclinical vascular damage represents a topic of great interest; examples include the pivotal role of carotid intima-media thickness in stratifying patients who are candidates for therapy initiation and the role of arterial stiffness in predicting future CV events in patients with coronary artery disease. ${ }^{13-15}$

The lack of an adequate evaluation of early atherosclerotic lesions of the lower limbs is a serious shortcoming, especially when considering the possible association of $\mathrm{PAD}$ with known $\mathrm{CV}$ risk factors and the possible predictive role of $\mathrm{PAD}$ and its involvement in global CV risk stratification.

To overcome these limits, in this study, we introduced a new ultrasonographic score, the ULLA score, which facilitates the categorization of atherosclerotic lesions of the lower limbs in all stages of PAD and associating these ultrasonographic categories with CV risk profiles. The main finding of our study is that the total severity index of the proposed ultrasonographic score is associated with age and male gender and with the other main traditional CV risk factors, that is, smoking, hypertension, diabetes, dyslipidemia, sedentary lifestyle and previous CV events, even after adjustment for age, gender and BMI.

Table 2 Associations between risk factors and ULLA scores

\begin{tabular}{|c|c|c|c|c|c|c|}
\hline & \multicolumn{2}{|c|}{ Total severity } & \multicolumn{2}{|c|}{ Proximal } & \multicolumn{2}{|c|}{ Distal } \\
\hline & Univariate $O R$ & Multivariate $O R$ & Univariate OR & Multivariate $O R$ & Univariate $O R$ & Multivariate $O R$ \\
\hline Age (1 year) & $1.08(1.06,1.10)$ & - & $1.07(1.05,1.09)$ & - & $1.10(1.08,1.13)$ & - \\
\hline Male gender & $4.17(2.74,6.34)$ & - & $3.99(2.61,6.09)$ & - & $3.21(2.10,4.93)$ & - \\
\hline $\mathrm{BMI}^{\mathrm{a}}\left(1 \mathrm{~kg} \mathrm{~m}^{-2}\right)$ & $0.97(0.93,1.02)$ & - & $0.97(0.93,1.02)$ & - & $0.97(0.92,1.02)$ & - \\
\hline Packs per year (1U) & $1.03(1.02,1.04)$ & $1.02(1.02,1.03)$ & $1.03(1.02,1.04)$ & $1.03(1.02,1.04)$ & $1.02(1.01,1.03)$ & $1.02(1.01,1.03)$ \\
\hline \multicolumn{7}{|l|}{ Smoking status ${ }^{b}$} \\
\hline Former & $2.73(1.76,4.25)$ & $1.62(0.95,2.78)$ & $2.71(1.74,4.22)$ & $1.61(0.94,2.75)$ & $1.87(1.19,2.92)$ & $1.14(0.65,2.00)$ \\
\hline Active & $1.94(1.10,3.44)$ & $2.65(1.40,5.01)$ & $2.10(1.17,3.76)$ & $2.77(1.45,5.29)$ & $1.03(0.57,1.87)$ & $1.58(0.81,3.11)$ \\
\hline Hypertension & $2.91(1.87,4.53)$ & $2.23(1.40,3.57)$ & $2.96(1.90,4.63)$ & $2.26(1.41,3.63)$ & $2.65(1.68,4.18)$ & $1.90(1.17,3.10)$ \\
\hline Diabetes & $2.36(1.55,3.58)$ & $1.94(1.24,3.02)$ & $2.13(1.40,3.25)$ & $1.75(1.12,2.73)$ & $2.71(1.75,4.20)$ & $2.41(1.50,3.87)$ \\
\hline Dyslipidemia & $1.34(0.90,2.00)$ & $1.52(1.01,2.30)$ & $1.48(0.99,2.22)$ & $1.62(1.08,2.45)$ & $1.04(0.69,1.57)$ & $1.05(0.68,1.61)$ \\
\hline CV family history & $1.00(0.62,1.61)$ & $1.63(0.99,2.67)$ & $0.94(0.59,1.52)$ & $1.38(0.85,2.26)$ & $0.96(0.59,1.57)$ & $1.76(1.04,2.96)$ \\
\hline Sedentary & $1.82(1.18,2.83)$ & $1.77(1.12,2.81)$ & $1.41(0.91,2.19)$ & $1.30(0.82,2.07)$ & $2.26(1.42,3.58)$ & $2.21(1.34,3.64)$ \\
\hline CV events & $3.33(2.07,5.36)$ & $1.95(1.17,3.23)$ & $3.69(2.28,5.99)$ & $2.22(1.33,3.72)$ & $2.98(1.83,4.83)$ & $1.77(1.04,3.00)$ \\
\hline
\end{tabular}

Abbreviations: BMI, body mass index; CV, cardiovascular; OR, odds ratio; ULLA, ultrasonographic lower limbs atherosclerosis.

aMultivariate models adjusted for age, gender and BMI.

beference group, never smoked. 
Table 3 Associations between risk factors and ULLA scores among participants with normal ABI

\begin{tabular}{|c|c|c|c|c|c|c|}
\hline & \multicolumn{2}{|c|}{ Total severity } & \multicolumn{2}{|c|}{ Proximal } & \multicolumn{2}{|c|}{ Distal } \\
\hline & Univariate $O R$ & Multivariate $O R$ & Univariate $O R$ & Multivariate $O R$ & Univariate $O R$ & Multivariate $O R$ \\
\hline Male gender & $3.16(1.94,5.15)$ & - & $2.93(1.78,4.80)$ & - & $2.72(1.63,4.54)$ & - \\
\hline $\mathrm{BMI}^{\mathrm{a}}\left(1 \mathrm{~kg} \mathrm{~m}^{-2}\right)$ & $1.02(0.97,1.07)$ & - & $1.02(0.96,1.07)$ & - & $1.02(0.97,1.08)$ & - \\
\hline Packs per year (1 U) & $1.02(1.01,1.04)$ & $1.03(1.01,1.04)$ & $1.02(1.01,1.04)$ & $1.02(1.01,1.04)$ & $1.01(1.00,1.02)$ & $1.02(1.00,1.03)$ \\
\hline Former & $2.14(1.28,3.58)$ & $1.49(0.81,2.76)$ & $1.92(1.15,3.22)$ & $1.31(0.72,2.41)$ & $1.67(0.98,2.84)$ & $1.18(0.62,2.24)$ \\
\hline Active & $1.17(0.61,2.25)$ & $1.95(0.96,3.97)$ & $1.15(0.59,2.23)$ & $1.80(0.87,3.70)$ & $0.58(0.29,1.17)$ & $1.09(0.50,2.37)$ \\
\hline Hypertension & $2.78(1.68,4.60)$ & $2.17(1.26,3.75)$ & $3.03(1.82,5.04)$ & $2.35(1.34,4.10)$ & $2.37(1.39,4.03)$ & $1.61(0.90,2.87)$ \\
\hline Diabetes & $2.57(1.55,4.26)$ & $2.32(1.35,3.99)$ & $2.19(1.31,3.66)$ & $1.95(1.12,3.39)$ & $2.97(1.74,5.07)$ & $2.75(1.54,4.90)$ \\
\hline Dyslipidemia & $1.63(1.01,2.63)$ & $1.66(1.01,2.71)$ & $1.86(1.15,3.01)$ & $1.85(1.13,3.04)$ & $1.17(0.71,1.93)$ & $1.06(0.63,1.78)$ \\
\hline CV family history & $1.15(0.65,2.05)$ & $1.94(1.07,3.53)$ & $0.92(0.51,1.64)$ & $1.30(0.72,2.38)$ & $1.15(0.63,2.11)$ & $2.13(1.12,4.05)$ \\
\hline
\end{tabular}

Abbreviations: $\mathrm{ABI}$, ankle-brachial index; BMI, body mass index; CV, cardiovascular; OR, odds ratio; ULLA, ultrasonographic lower limbs atherosclerosis.

a Multivariate models adjusted for age, gender and BMI.

Reference group, never smoked.

Table 4 Associations between risk factors and ULLA scores among participants with no symptoms

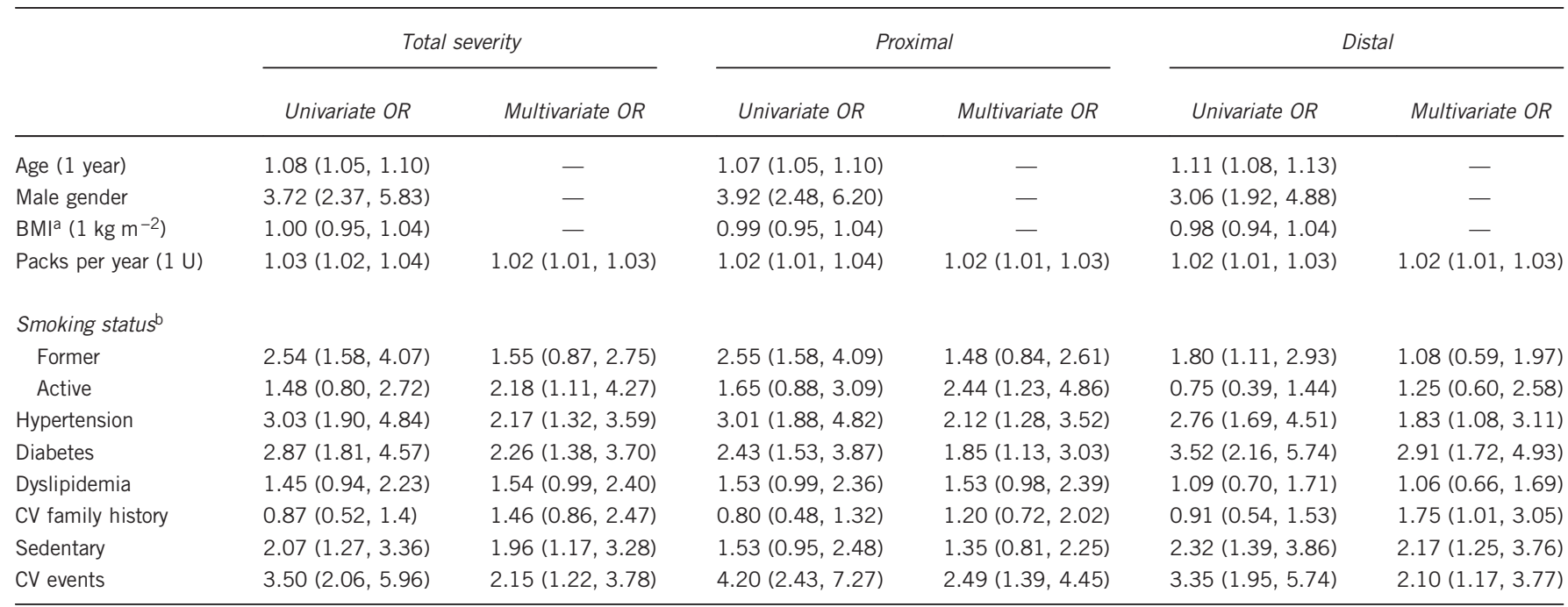

Abbreviations: ULLA, ultrasonographic lower limbs atherosclerosis; BMI, body mass index; CV, cardiovascular; OR, odds ratio.

a Multivariate models adjusted for age, gender and BMI.

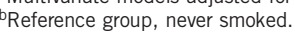

Moreover, our data confirm that specific CV risk factors are selectively associated with the proximal or distal districts; in particular, smoking status and dyslipidemia are selectively associated with the proximal district score, whereas CV family history and sedentary lifestyle are selectively associated with the distal district score. Packs per year of smoking, hypertension and diabetes are significantly associated with both the proximal and distal district scores. However, for hypertension, the magnitude of the association is larger for the proximal district score, whereas for diabetes it is larger for the distal district score. Numerous hypotheses have been proposed to explain the site selectivity of atherosclerotic lesions, including hemodynamic stress related to arterial geometry and anatomic, cellular or biochemical variations in the arterial wall. ${ }^{16}$

These findings confirm what is already known about the correlation between PAD and CV risk factors and with regard to specific districts and single $\mathrm{CV}$ risk factors. The findings extend the relationships established in previous studies to all stages of PAD, including early, asymptomatic stages. The current data, in fact, generally have been obtained from studies of patients undergoing endovascular treatment for advanced stages of PAD (generally Fontaine stages III-IV), which correspond to the detection of hemodynamically significant lesions through instrumental imaging. Moreover, the diagnostic tool used in most studies has been angiography, which is considered the gold standard for grading atherosclerotic lesions of the lower extremities. ${ }^{17}$ Nonetheless, some limitations for this technique must be considered. First, angiography only allows the specific study of the proximal arteries, with segments distal to the popliteal artery often not considered because of their relatively poor visualization. Moreover, in many angiographic studies, disease severity was based on the number of occlusions, and the atherosclerotic pattern was defined only by the endovascular target lesions treated. ${ }^{18}$ Finally, in several studies, subjects with stenosis that did not reach $50 \%$ in any of the segments of the lower 
limb arterial tree were excluded. ${ }^{19}$ Consequently, angiography does not provide information about early atherosclerotic lesions, and the entire atherosclerotic burden is often not considered for analysis.

Other studies have used noninvasive techniques to assess PAD by detecting perfusion effects rather than the degree or site of stenosis within single arteries. Most of these include ABI evaluation, a measurement comparing the ankle systolic blood pressure to the brachial artery systolic blood pressure. This test is simple, noninvasive, risk free and inexpensive, and with an $\mathrm{ABI}$ value $<0.90$ indicative of $\mathrm{PAD}$, it has acceptable diagnostic performance properties for PAD screening (sensitivity 79-95\%; specificity 95-100\%). ${ }^{20,21}$ However, $\mathrm{ABI}$ results are abnormal only in the presence of advanced arterial lesions able to reduce ankle systolic blood pressure; therefore, early atherosclerotic lesions of the lower limbs cannot be detected by ABI measurement. Moreover, ABI could produce 'pseudonormal' values in the presence of arterial stiffening; thus, $\mathrm{ABI}$ is an imperfect marker of lower limb perfusion, especially in diabetic patients. ${ }^{22}$

As mentioned above, the proposed ULLA score overcomes these limitations, allowing a complete evaluation of the entire lower limb atherosclerotic burden and extending the results to all stages of PAD, including early stages. Moreover, after excluding patients with altered $\mathrm{ABI}$ or with symptoms suggestive of $\mathrm{PAD}$, our results remained substantially unchanged, confirming the robustness of the proposed score even in the early, preclinical stages of PAD. This result is especially important when we consider that only $10 \%$ of patients affected by PAD have the classic symptoms of intermittent claudication; most patients report atypical symptoms or no symptoms at all. ${ }^{23}$ The only reported difference is represented by the loss of association between previous CV events and ULLA scores in the 241 patients with normal $\mathrm{ABI}$, even after adjusting for age and the other traditional CV risk factors. It is plausible that this result reflects the reduced systemic involvement of vascular damage in these patients.

Considering PAD at all stages of the disease can have a role also in the recent research revealing the role of PAD involvement in $\mathrm{CV}$ risk stratification. Risk stratification in CV disease prevention represents a major goal for twenty-first century medicine. Assessment of traditional $\mathrm{CV}$ risk factors, such as blood pressure and low-density lipoprotein cholesterol levels, remains the cornerstone of risk estimation; however, a residual risk may remain even after controlling for traditional $\mathrm{CV}$ risk factors. Therefore, new markers, mainly those related to inflammation and genetic profiles, have recently been added to scoring systems to better assess the risk of CV disease, together with instrumental techniques for measuring asymptomatic organ damage. ${ }^{24,25}$ Among these instrumental techniques, those techniques that evaluate the cardiac and carotid districts seem to be the most effective. In particular, the independent prognostic value of carotid ultrasonography with evaluation of carotid intima-media thickness and plaques in predicting $\mathrm{CV}$ events has been widely demonstrated. ${ }^{26-28}$ Recently, the presence of PAD has also been considered in the assessment of organ damage to better define the existing CV risk profile. Patients affected by ABI-assessed PAD have higher CV mortality and morbidity than age-matched controls without PAD, even after adjusting for traditional CV risk factors using the Framingham Risk Score, and these findings are similar for individuals with symptomatic and asymptomatic PAD. ${ }^{10-12}$ Studies involving ultrasound evaluation of the lower limb districts have shown the femoral intima-media thickness measurement to be an indicator of symptomatic coronary atherosclerosis. ${ }^{29-32}$

The proposed ULLA score for PAD, which is able to categorize earlier stages of the disease, could change the predictive value of PAD in assessing CV risk. In particular, our findings could improve the identification of individuals with a low-moderate 10-year risk for CV disease based on classical scoring systems but a moderate-high lifetime risk, allowing these individuals to benefit from early interventions designed to prevent progression to the high-risk group in later life. Moreover, exploring the possible presence of subclinical atherosclerosis in the lower limb districts could be of interest because multiple organ damage carries a worse prognosis than single organ involvement. ${ }^{33,34}$ In individuals with one or more classical risk factors who do not appear to have a high total CV risk according to current methods of quantification, subclinical organ damage is common. The Anglo-Scandinavian Cardiac Outcomes Trial-Lipid-Lowering Arm demonstrated that treatment of patients with indicators of subclinical CV disease could reduce CV events. ${ }^{35}$

Another important implication of the ULLA score is the ability to compare the real association of CV risk factors with the atherosclerotic lesion distribution in different districts. This association is often deduced through instrumental methods with different sensitivities. ${ }^{36}$ Moreover, a complete tool for identifying PAD stages in all patients is fundamental for the assessment of $\mathrm{PAD}$ progression; currently, most studies conducted for this purpose have used only ABI or angiographic evaluation, establishing that smoking and diabetes mellitus are the most important factors in PAD progression. ${ }^{37,38}$ The use of a more appropriate instrumental technique that is more accurate, especially in identifying early lesions, could also facilitate the association of PAD with novel biomarkers of the atherosclerosis process associated with pathways of inflammation, lipoprotein and adipocyte metabolism, hemodynamic stress, calcification and hemostasis. ${ }^{39,40}$

Certainly, the most interesting future research on the proposed ULLA score will be studying its predictive properties with respect to the risk of CV event development. In fact, it is well known that only a small percentage of patients with $\mathrm{PAD}$ require lower extremity intervention; thus, screening for PAD should be not beneficial as much in reducing the risk of symptomatic PAD or ischemic limb event, rather than it should be help identify those who need aggressive preventive measures for $\mathrm{CV}$ and cerebrovascular risk reduction.

\section{CONFLICT OF INTEREST}

The authors declare no conflict of interest.

1 Lloyd-Jones D, Adams R, Carnethon M, De Simone G, Ferguson TB, Flegal K, Ford E, Furie K, Go A, Greenlund K, Haase N, Hailpern S, Ho M, Howard V, Kissela B, Kittner S, Lackland D, Lisabeth L, Marelli A, McDermott M, Meigs J, Mozaffarian D, Nichol G, O'Donnell C, Roger V, Rosamond W, Sacco R, Sorlie P, Stafford R, Steinberger J, Thom T, Wasserthiel-Smoller S, Wong N, Wylie-Rosett J, Hong Y, American Heart Association Statistics Committee and Stroke Statistics Subcommittee. Heart disease and stroke statistics-2009 update. A report from the American Heart Association Statistics Committee and Stroke Statistics Subcommittee. Circulation 2009; 119: 480-486.

2 Pasternak RC, Criqui MH, Benjamin EJ, Fowkes FGR, Isselbacher EM, McCullough PA, Wolf PA, Zheng ZJ. AHA conference proceedings: Atherosclerotic Vascular Disease Conference: Writing Group I: epidemiology. Circulation 2004; 109: 2605-2612.

3 Criqui MH, Browner D, Fronek A, Klauber MR, Coughlin S, Barrett-Connor E, Gabriel S. Peripheral arterial disease in large vessels is epidemiologically distinct from small vessel disease. Am J Epidemiol 1989; 129: 1110-1119.

4 Aboyans V, Locroix P, Criqui MH. Large and small vessels atherosclerosis: similarities and differences. Progr Cardiovasc Dis 2007; 50: 112-125.

5 Fowkes FGR, Housley E, Riemermsa RA, Macintyre CC, Cawood EH, Prescott RJ, Ruckley CV. Smoking, lipids, glucose intolerance, and blood pressure as risk factors for peripheral arterial disease compared with ischemic heart disease in the Edinburgh Artery Study. Am J Epidemiol 1992; 135: 331-340.

6 Diehm N, Shang A, Silvestro A, Do D, Dick F, Schmidli J, Mahler F, Baumgartner I. Association of cardiovascular risk factors with pattern of lower limb atherosclerosis in 2659 patients undergoing angioplasty. Eur J Endovasc Surg 2006; 31: 59-63.

7 Handelsman Y, Bloomgarden ZT, Grunberger G, Umpierrez G, Zimmerman RS, Bailey TS, Blonde L, Bray GA, Cohen AJ, Dagogo-Jack S, Davidson JA, Einhorn D, Ganda OP, Garber AJ, Garvey WT, Henry RR, Hirsch IB, Horton ES, Hurley DL, 
Jellinger PS, Jovanovič L, Lebovitz HE, LeRoith D, Levy P, McGill JB, Mechanick JI, Mestman JH, Moghissi ES, Orzeck EA, Pessah-Pollack R, Rosenblit PD, Vinik AI, Wyne K, Zangeneh F. American Association of clinical Endocrinologists and American College of Endocrinology — clinical practice guidelines for developing a diabetes mellitus comprehensive care plan-2015. Endocr Pract 2015; 21: 1-87.

8 Mancia G, Fagard R, Narkiewicz K, Redón J, Zanchetti A, Böhm M, Christiaens T, Cifkova R, De Backer G, Dominiczak A, Galderisi M, Grobbee DE, Jaarsma T, Kirchhof P, Kjeldsen SE, Laurent S, Manolis AJ, Nilsson PM, Ruilope LM, Schmieder RE, Sirnes PA, Sleight P, Viigimaa M, Waeber B, Zannad F, Task Force Members. 2013 ESH/ESC Guidelines for the management of arterial hypertension: the Task Force for the management of arterial hypertension of the European Society of Hypertension (ESH) and of the European Society of Cardiology (ESC). J Hypertens 2013; 31: 1281-1357.

9 National Cholesterol Education Program (NCEP) Expert Panel. Third Report of the National Cholesterol Education Program (NCEP) Expert Panel on Detection, Evaluation, and Treatment of High Blood Cholesterol in Adults (Adult Treatment Panel III) final report. Circulation 2002; 106: 3143-3421.

10 Criqui MH, Langer RD, Fronek A, Feigelson HS, Klauber MR, McCann TJ, Browner D. Mortality over a period of 10 years in patients with peripheral arterial disease. $N$ Engl J Med 1992; 326: 381-386.

11 Leng G, Fowkes F, Lee A, Dunbar J, Housley E, Ruckley C. Use of ankle brachial pressure index to predict cardiovascular events and death: a cohort study. BMJ 1996; 313: 1440-1444.

12 Fowkes FG, Murray GD, Butcher I, Heald CL, Lee RJ, Chambless LE, Folsom AR, Hirsch AT, Dramaix M, de Backer G, Wautrecht JC, Kornitzer M, Newman AB, Cushman M, Sutton-Tyrrell K, Fowkes FG, Lee AJ, Price JF, d'Agostino RB, Murabito JM, Norman PE, Jamrozik K, Curb JD, Masaki KH, Rodríguez BL, Dekker JM, Bouter LM, Heine RJ, Nijpels G, Stehouwer CD, Ferrucci L, McDermott MM, Stoffers HE, Hooi JD, Knottnerus JA, Ogren M, Hedblad B, Witteman JC, Breteler MM, Hunink MG, Hofman A, Criqui MH, Langer RD, Fronek A, Hiatt WR, Hamman R, Resnick HE, Guralnik J, McDermott MM. Ankle brachial index combined with Framingham risk score to predict cardiovascular events and mortality: a meta-analysis. JAMA 2008; 300: 197-208.

13 Plantinga Y, Dogan S, Grobbee DE, Bots ML. Carotid intima-media thickness measurement in cardiovascular screening programmes. Eur J Cardiovasc Prev Rehabil 2009; 16: 639-644.

14 Ring M, Eriksson MJ, Zierath JR, Caidahl K. Arterial stiffness estimation in healthy subjects: a validation of oscillometric (Arteriograph) and tonometric (SphygmoCor) techniques. Hypertens Res 2014; 37: 999-1007.

15 Otsuka K, Fukuda S, Shimada K, Suzuki K, Nakanishi K, Yoshiyama M, Yoshikawa J. Serial assessment of arterial stiffness by cardio-ankle vascular index for prediction of future cardiovascular events in patients with coronary artery disease. Hypertens Res 2014; 37: 1014-1020.

16 McGill HC Jr, McMahan CA, Herderick EE, Tracy RE, Malcom GT, Zieske AW, Strong JP. Effects of coronary heart disease risk factors on atherosclerosis of selected regions of the aorta and right coronary artery. PDAY Research Group. Pathobiological determinants of atherosclerosis in youth. Arterioscler Thromb Vasc Biol 2000; 20 836-845.

17 Bollinger A, Breddin K, Hess H, Heystraten FM, Kollath J, Konttila A, Pouliadis G Marshall M, Mey T, Mietaschk A, Roth FJ, Schoop W. Semiquantitative assessment of lower limb atherosclerosis from routine angiographic images. Atherosclerosis 1981; 38 339-346.

18 Smith FB, Lee AJ, Fowkes FGR, Lowe GDO, Rumley A. Variation in cardiovascular risk factors by angiographic site of lower limb atherosclerosis. Eur J Vasc Endovasc Surg 1996; 11: 340-346

19 Ozkan U, Oguzkurt L, Tercan F. Atherosclerotic risk factors and segmental distribution in symptomatic peripheral artery disease. J Vasc Interv Radiol 2009; 20. 437-441.

20 Greenland P, Abrams J, Aurigemma GP, Bond MG, Clark LT, Criqui MH, Crouse JR III, Friedman L, Fuster V, Herrington DM, Kuller LH, Ridker PM, Roberts WC, Stanford W, Stone N, Swan HJ, Taubert KA, Wexler L. Prevention Conference V: beyond secondary prevention: identifying the high-risk patient for primary prevention: noninvasive tests of atherosclerotic burden: writing group III. Circulation 2000; 101: e16-e22.

21 Hirsch AT, Haskal ZJ, Hertzer NR, Bakal CW, Creager MA, Halperin JL, Hiratzka LF, Murphy WR, Olin JW, Puschett JB, Rosenfield KA, Sacks D, Stanley JC, Taylor LM Jr, White CJ, White J, White RA, Antman EM, Smith SC Jr, Adams CD, Anderson JL, Faxon DP, Fuster V, Gibbons RJ, Hunt SA, Jacobs AK, Nishimura R, Ornato JP, Page RL, Riegel B; American Association for Vascular Surgery; Society for Vascular Surgery; Society for Cardiovascular Angiography and Interventions; Society for Vascular Medicine and Biology; Society of Interventional Radiology; ACC/AHA Task Force on Practice Guidelines Writing Committee to Develop Guidelines for the Management of Patients With Peripheral Arterial Disease; American Association of Cardiovascular and Pulmonary Rehabilitation; National Heart, Lung, and Blood Institute; Society for Vascular Nursing; TransAtlantic Inter-Society Consensus; Vascular Disease Foundation. ACC/AHA 2005 Practice Guidelines for the management of patients with periphera arterial disease (lower extremity, renal, mesenteric, and abdominal aortic): a collaborative report from the American Association for Vascular Surgery/Society for Vascular Surgery, Society for Cardiovascular Angiography and Interventions, Society for Vascular Medicine and Biology, Society of Interventional Radiology, and the ACC/AHA Task Force on Practice Guidelines (Writing Committee to Develop Guidelines for the Management of Patients With Peripheral Arterial Disease): endorsed by the American Association of Cardiovascular and Pulmonary Rehabilitation; National Heart, Lung, and Blood Institute; Society for Vascular Nursing, TransAtlantic Inter-Society Consensus; and Vascular Disease Foundation. Circulation 2006; 113: e463-e654.
22 Orchard DJ, Strandness DE Jr. Assessment of peripheral vascular disease in diabetes: reports and recommendations of an international workshops by ADA and AHA September 18-20, 1992, New Orleans, Louisiana. Circulation 1993; 88: 819-828.

23 Hirsch A, Criqui M, Treat-Jacobson D, Regensteiner J, Creager M, Olin J, Krook SH, Hunninghake DB, Comerota AJ, Walsh ME, McDermott MM, Hiatt WR. Peripheral arterial disease detection, awareness, and treatment in primary care. JAMA 2001; 286: 1317-1324

24 Ridker PM, Buring JE, Rifai N, Cook NR. Development and validation of improved algorithms for the assessment of global cardiovascular risk in women: the Reynolds Risk Score. JAMA 2007; 297: 611-619.

25 Ridker PM, Paynter NP, Rifai N, Gaziano JM, Cook NR. C-reactive protein and parental history improve global cardiovascular risk prediction: the Reynolds Risk Score for men. Circulation 2008; 118: 2243-2251.

26 Johnsen SH, Mathiesen EB, Joakimsen O, Stensland E, Wilsgaard T, Løchen ML, $\mathrm{Njølstad} \mathrm{I,} \mathrm{Arnesen} \mathrm{E.} \mathrm{Carotid} \mathrm{atherosclerosis} \mathrm{is} \mathrm{a} \mathrm{stronger} \mathrm{predictor} \mathrm{of} \mathrm{myocardial}$ infarction in women than in men: a 6-year follow-up study of 6226 persons: the Tromso Study. Stroke 2007; 38: 2873-2880.

27 Lorenz MW, Markus HS, Bots ML, Rosvall M, Sitzer M. Prediction of clinical cardiovascular events with carotid intima-media thickness: a systematic review and meta-analysis. Circulation 2007; 115: 459-467.

28 Prabhakaran S, Singh R, Zhou X, Ramas R, Sacco RL, Rundek T. Presence of calcified carotid plaque predicts vascular events: the Northern Manhattan Study. Atherosclerosis 2007: 195: e197-e201.

29 Lekakis JP, Papamichael C, Papaioannou TG, Stamatelopoulos KS, Cimponeriu A Protogerou AD, Kanakakis J, Stamatelopoulos SF. Intima-media thickness score from carotid and femoral arteries predicts the extent of coronary artery disease: intima-media thickness and CAD. Int J Cardiovasc Imag 2005; 21: 495-501.

30 Lekakis JP, Papamichael CM, Cimponeriu AT, Stamatelopoulos KS, Papaioannou TG, Kanakakis J, Alevizaki MK, Papapanagiotou A, Kalofoutis AT, Stamatelopoulos SF. Atherosclerotic changes of extracoronary arteries are associated with the extent of coronary atherosclerosis. Am J Cardiol 2000; 85: 949-952.

31 Sosnowski C, Pasierski T, Janeczko-Sosnowska E, Szulczyk A, Dabrowski R, Woźniak J, Sumiński A, Ruzyłło W. Femoral rather than carotid artery ultrasound imaging predicts extent and severity of coronary artery disease. Kardiol Pol 2007; 65: 760-766.

32 Held C, Hjemdahl P, Eriksson SV, Björkander I, Forslund L, Rehnqvist N. Prognostic implications of intima-media thickness and plaques in the carotid and femoral arteries in patients with stable angina pectoris. Eur Heart J 2001; 22: 62-72.

33 Olsen MH, Wachtell K, Bella JN, Palmieri V, Gerdts E, Smith G, Nieminen MS, Dahlöf B, Ibsen H, Devereux RB. Albuminuria predicts cardiovascular events independently of left ventricular mass in hypertension: a LIFE substudy. J Hum Hypertens 2004; 18: 453-459.

34 Tsioufis C, Vezali E, Tsiachris D, Dimitriadis K, Taxiarchou E, Chatzis D, Thomopoulos C Syrseloudis D, Stefanadi E, Mihas C, Katsi V, Papademetriou V, Stefanadis C. Left ventricular hypertrophy versus chronic kidney disease as predictors of cardiovascular events in hypertension: a Greek 6-year-followup study. J Hypertens 2009; 27: 744-752.

35 Sever PS, Dahlöf B, Poulter NR, Wedel H, Beevers G, Caulfield M, Collins R, Kjeldsen SE, Kristinsson A, McInnes GT, Mehlsen J, Nieminen M, O'Brien E, Ostergren J, ASCOT investigators. Prevention of coronary and stroke events with atorvastatin in hypertensive patients who have average or lower-than-average cholesterol concentrations, in the Anglo-Scandinavian Cardiac Outcomes Trial-Lipid Lowering Arm (ASCOT-LLA): a multicentre randomised controlled trial. Lancet 2003; 361: 1149-1158.

36 Poulsen MK, Nybo M, Dahl J, Hosbond S, Poulsen TS, Johansen A, Høilund-Carlsen PF, Beck-Nielsen H, Rasmussen LM, Henriksen JE. Plasma osteoprotegerin is related to carotid and peripheral arterial disease, but not to myocardial ischemia in type 2 diabetes mellitus. Cardiovasc Diabetol 2011; 10: 76.

37 Aboyans V, Criqui MH, Denenberg JO, Knoke JD, Ridker PM, Fronek A. Risk factors for progression of peripheral arterial disease in large and small vessels. Circulation 2006; 113: 2623-2629.

38 Ozkan U, Oguzkurt L, Tercan F. Atherosclerotic risk factors and segmental distribution in symptomatic peripheral artery disease. J Vasc Interv Radiol 2009; 20: 437-441.

39 Ye Z, Ali Z, Klee GG, Mosley TH Jr, Kullo IJ. Associations of candidate biomarkers of vascular disease with the ankle-brachial index and peripheral arterial disease. $\mathrm{Am} J$ Hypertens 2013; 26: 495-502.

40 Biscetti F, Porreca CF, Bertucci F, Straface G, Santoliquido A, Tondi P, Angelini F, Pitocco D, Santoro L, Gasbarrini A, Landolfi R, Flex A. TNFRSF11B gene polymorphisms increased risk of peripheral arterial occlusive disease and critical limb ischemia in patients with type 2 diabetes. Acta Diabetol 2014; 51: 1025-1032.

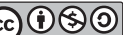

This work is licensed under a Creative Commons Attribution-NonCommercial-ShareAlike 4.0 International License. The images or other third party material in this article are included in the article's Creative Commons license, unless indicated otherwise in the credit line; if the material is not included under the Creative Commons license, users will need to obtain permission from the license holder to reproduce the material. To view a copy of this license, visit http://creativecommons.org/licenses/bync-sa/4.0/

(C) The Author(s) 2016 